\title{
EPISTEMES Y CAMBIOS CIENTÍFICOS: EL ANÁLISIS DE UN CASO DEL CAMPO HISTÓRICO *
}

MARÍA INÉS MUDROVCIC

UNIVERSiDAD NACIONAL DEL COMAHUE

CONSEJO NACIONAL de INVESTIGACIONES CIENTIFICAS Y TÉCNICAS

Quizá la revolución más profunda que provocó Kuhn no fue la de arrojar a los epistemólogos esa "parafernalia" de paradigmas, revoluciones cientificas e inconmensurabilidades, sino la de haber transgredido la "zona prohibida". Kuhn, miembro de la comunidad de científicos naturales, pasó un año (de 1958 a 1959) en el Centro de Estudios Avanzados sobre las Ciencias de la Conducta. Esta convivencia con científicos sociales no sólo permitió visualizar problemas nuevos, sino trasladarlos al campo de su propia disciplina. ${ }^{2}$ Este trabajo trata, en parte, de la influencia recíproca entre comunidades científicas diferentes y su posible repercusión en los cambios producidos en el interior de las mismas. El ejemplo particular que discutiré pertenece al campo de las disciplinas sociales: el cambio de esquema conceptual que se produce durante la primera mitad del siglo XVIII en el ámbito de la historia. Dicho cambio tiene por protagonista a Voltaire y su eje principal se articula alrededor del nuevo papel que le confiere a la razón en los asuntos históricos. En primer lugar, introduciré algunas precisiones acerca del alcance de ciertos conceptos tal como serán usados en el trabajo. Luego, presentaré el caso concreto y, por último, esbozaré algunas consideraciones provisorias acerca de la racionalidad de los cambios científicos y su inserción en el marco de una historia epistémica. ${ }^{3}$ Esta última cuestión será discutida a partir de los siguientes incisos:

- Agradezco al doctor León Olivé sus comentarios y observaciones a la primera versión de este trabajo.

1 Cfr. Mario Otero, "El concepto de racionalidad. Un caso: la polémica Frege-Hilbert", en Olivé, Racionalidad, Siglo XXI, México, 1988, p. 212.

2 T.S. Kuhn, "Introducción", en La estructura de la las revoluciones cientificas, FCE, México, 1971.

3 No quiero dejar de mencionar el trabajo de O. Nudler, "Hacia un modelo de la historia epistémica occidental", Manuscrito, vol. 14, no. 2, diciembre, 1991, que me ha servido como fuente para algunos de los conceptos que aquí se vierten. 
1. El concepto de racionalidad se determina desde su contexto histórico.

2. Si contextualizamos la racionalidad, existirán ciertos elementos con los cuales los miembros de determinada comunidad mantendrán una relación de ceguera y no de oposición por ser éstos avant la lettre.

3. Los cambios de las diferentes comunidades socioculturales no se producen simultánemente.

4. Son los cambios de las diferentes comunidades en su conjunto - $-\mathrm{y}$ no sólo los de la comunidad científica- los que proveen las relaciones de sentido que constituyen las grandes epistemes.

5. Se admite cierto grado de racionalidad como condición de posibilidad de la historia, en general, y de la historia epistémica, en particular.

Quisiera, en primer término, distinguir entre dos conceptos a los que, a menudo, se les atribuye la misma referencialidad: episteme y paradigma. Con el término "episteme" significaremos un marco de sentido amplio que confiere orden al mundo y que se articula entre dos límites caracterizados como mutaciones. Estas mutaciones o cambios temporales señalan las transformaciones de las epistemes. Siguiendo en esto a Foucault en Las palabras y las cosas, diremos que las epistemes son "los códigos fundamentales de una cultura - los que rigen su lenguaje, sus esquemas perceptivos, sus cambios, sus técnicas, sus valores, la jerarquía de sus prácticas- fijan de antemano para cada hombre los órdenes empíricos con los cuales tendrá algo que ver y dentro de los que se reconocerá". ${ }^{4}$ Se puede discutir con Hayden White ${ }^{5}$ si el contenido estructural profundo de lo que denominamos aquí epistemes es poético en general y lingüístico, en particular. Pero, en todo caso, funcionan como trasfondo precrítico de los paradigmas, y en este sentido, constituyen metaparadigmas.

De lo que llevamos dicho, se desprende que el concepto de paradigma tiene un alcance más reducido. Para nuestros fines, paradigma se acerca a lo que Kuhn acotó como "matriz disciplinaria": "'Disciplinaria' porque se refiere a la posesión común de quienes practican una disciplina particular; 'matriz', porque está compuesta por elementos ordenados de varias

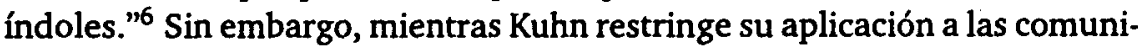
dades de científicos naturales, quiero hacer extensivo su uso a las diferentes comunidades socioculturales. Esto último me permite hablar, por ejemplo,

4 M. Foucault, Las palabras y las cosas, Siglo XXI, México, 1981, p. 5.

5 H. White, "Preface", en Metahistory, John Hopkins University Press, Baltimore, 1973.

6 T.S. Kuhn, op. cit., p. 280. 
del paradigma compartido por los miembros de una comuidad artística o religiosa. Distinguiremos en el interior de los mismos, una dimensión epistemológica, otra estética y una moral, operaciones teóricas en las que subyace un aspecto preteórico perteneciente a la episteme correspondiente. Asi, podremos diferenciar distintos paradigmas, pertenecientes a diferentes comunidades y a la misma episteme. En su interacción, los paradigmas proveen los marcos de sentido, generando un espacio de juego que hace posible las teorías y las prácticas en una época dada.

En lo que sigue trataré de abordar el cambio producido en la comunidad de los historiadores en el periodo comprendido entre fines del XVII y mediados del XVIII. Hacia la época en que Voltaire envía a D'Alembert su artículo "Histoire" para ser publicado en la Enciclopedia (28 de diciembre de 1756), su pensamiento histórico había llegado a su completa madurez. Sin duda, la Enciclopedia constituye uno de los textos centrales del Siglo de las Luces y representa la voz oficial del pensamiento iluminista. Coincidimos con Schargo ${ }^{7}$ y otros estudiosos, en que los conceptos que se vierten allí acerca del método histórico, la interpretación en historia o el papel de la historia son "los esperados". Comenzaremos, entonces, por analizar brevemente en qué consiste esa "posición oficial" con relación a la historia, para luego intentar mostrar la ruptura de ese orden conceptual.

Desde sus orígenes en Grecia, se emparenta la historia con la memoria. Esta tradición es recogida por Bacon que, en el Novum Organum, propone clasificar las ciencias de acuerdo con las facultades humanas: memoria, imaginación y razón. La historia pertenece al dominio de la memoria, la razón no desempeña aquí ningún papel activo y se encuentra reservada para la filosofía y la ciencia.

La influencia de Bacon es notable en la Enciclopedia y es particularmente interesante en el Discours préliminaire. D'Alembert inserta una "Explicación detallada de los conocimientos humanos", verdadera taxonomía que impone mediante el concepto un nuevo orden al campo empírico. Coloca allí, siguiendo a Bacon, la historia bajo el régimen de la memoria, caracterizándola en los siguientes términos: "La historia es de hechos, y los hechos conciernen a Dios, al hombre o a la naturaleza. Los hechos que corresponden a Dios pertenecen a la historia sagrada; los correspondientes al hombre pertenecen a la historia civil, y los correspondientes a la naturaleza constituyen la historia natural."

7 Cfr. H. Vyverberg, Human Nature, Cultural Diversity, and the French Enlightenment, Oxford University Press, Nueva York, 1989, p. 148. 
Aparentemente, el modelo propuesto por Diderot y D'Alembert no difería mayormente del de Bacon, y tanto es así que fueron acusados de plagio. Sin embargo, consciente del nuevo espacio instaurado, Diderot incluye el árbol de Bacon en el Prospectus e insta a la comparación. No es una cuestión de cosas sino de orden. ${ }^{8}$ De Bacon a la Enciclopedia se mantiene la filiación entre la memoria e historia. A la historia, en principio, se le encomienda la tarea de almacenar y resguardar hechos. Sin embargo, a la hora de considerar las "ramas" de cada árbol, son varias las diferencias que se nos presentan. Se ha invertido, exactamente, el lugar que ocupa la historia natural. Si en el árbol de Bacon ocupa un lugar marginal, en la Enciclopedia constituye una de las partes más amplias y que con mayor cuidado se confeccionó. ${ }^{9} \mathrm{Y}$ es este último problema el que, desde nuestro presente, despierta mayores interrogantes y posee mayores implicaciones. De un lado, es válido preguntarse qué entienden los ilustrados por historia natural y cuál es el sentido de su filiación con la memoria. Pero de otro, no deja de ser causa de asombro la temática que abarca y el orden que ocupa.

Con relación a la primera cuestión, la historia natural comprende los hechos de la naturaleza. $Y$ son hechos naturales tanto un animal como un cuerpo celeste; una moneda como un vegetal; una montaña como un terremoto. Todavía no existe la dicotomía orgánico/inorgánico (habrá que esperar hasta el siglo XIX para que nazca el nuevo concepto de vida). ${ }^{10}$

Los ilustrados están alejados de la idea de un "evolucionismo", de pensar los seres como resultados de procesos temporales, ${ }^{11}$ o las acciones humanas como productos históricos. Se hace, entonces, más patente la filiación historia-memoria, en tanto se centraliza en sólo uno de sus aspectos, el de recolección en detrimiento del de repetición. Se comprende la memoria en una de sus dimensiones, precisamente en aquella en que el pasado aparenta no tener edad y se confunde con el presente. Memoria es testimonio, facultad que proporciona conocimientos directos que son "los que recibimos directamente sin ninguna operación de nuestra voluntad". ${ }^{12}$ Se retorna al primitivo sentido griego de la memoria. Luego de años de oscuridad en que la labor del historiador consistía en copiar, comentar y traducir a los antiguos y que "se creía que, para ser sabios, bastaba con leer, y es mucho más fácil leer que ver", luego de años de repetir lo heredado, se retoma el

8 Prospectus de l'Encyclopédie, en Diderot, CEuvres complètes, París, vol. 11, p. 147. Se cita: Prospectus.

9 Cfr. Discours, XX, XXI.

10 Cfr. Foucault, op. cit., p. 130.

11 Ibid.

12 Discours, XV. 
sentido - presente en Heródoto y Tucídides- de recolectar lo observado. Es el auge de la historia reciente.

Pero este orden espacializado -es corriente la comparación con el mapamundi- ${ }^{13}$ impone una determinada jerarquía de seres. Y aquí pasamos a la segunda cuestión a la que aludíamos anteriormente. Diderot y D'Alembert colocan la historia natural luego de la historia del hombre y muestran su asombro ante el hecho de que "el autor célebre que nos sirve de guía en esta distribución ha situado en su sistema a la Naturaleza antes que al hombre, parece, por el contrario, que todo induce a colocar al hombre en el punto intermedio que separa de los cuerpos a Dios y los espíritus". ${ }^{14}$ Este orden no llamaría mayormente la atención a no ser por la jerarquía interna a partir de la que se organizan los seres que forman la historia natural.

La historia natural se divide en Uniformidades de la naturaleza, Desviaciones de la naturaleza y Usos de la naturaleza. Y en este último inciso se incluyen todas las "artes y oficios" que son resultado de "los diferentes usos que los hombres hacen de la Naturaleza". ${ }^{15}$ La pregunta que surge inmediatamente es, ¿qué hacen "las artes y oficios" formando parte de la historia natural?, ¿no es acaso un tema más propio de la historia del hombre ya que ésta tiene por objeto "sus acciones o sus conocimientos"? Diderot en el Prospectus da cuenta de que con la parte de la historia natural "obligada a diferentes usos" podría hacerse una rama de la historia civil, pero despacha la cuestión sin darle mayor trascendencia.

Era, sin duda, la parte más original de la Enciclopedia, pues "entre los que han tratado sobre el tema el uno no estaba lo bastante enterado de lo que tenía que decir [...] y el otro no ha hecho más que tocar la materia, tratándola como gramático más que como artista". ${ }^{16}$ Era la parte más engorrosa puesto que "como hay poca costumbre tanto de escribir como de leer escritos sobre las artes, las cosas han resultado difíciles de explicar de una manera inteligible". ${ }^{17}$ En suma, una de las partes por las que se define la Enciclopedia instaura su espacio en el objeto sobre el que recae (naturaleza) y no en el sujeto que la efectúa (hombre).

13 Cfr. R. Damton, La gran matanza de gatos y otros episodios en la historia de la cultura francesa, FCE, México, 1987, p. 196.

14 Discours, XVII.

$15 \mathrm{Al}$ respecto, D'Alembert dice: "He aquí el método que se ha seguido para cada arte. Se ha tratado: 10. De la materia, de los lugares en que se encuentra, de la manera como se prepara [...] 20. De las principales obras que con ella se hacen [...] 3o. Hemos dado el nombre, la descripción y la forma de las herramientas [... ] 40. Hemos explicado y representado la mano de obra [... ] 5o. Hemos recogido y definido lo más exactamente posible los términos propios del oficio." Discours, XXX1X.

16 Prospectus, p. 116.

17 Ibid., p. 117. 
Si bien en el espacio configurado por el "árbol del conocimiento" el paradigma de la historia propuesto se mantiene bajo el dominio de la memoria, hay una ruptura que nos indica que nos encontramos con un orden nuevo. En la Enciclopedia - a diferencia del "árbol" de Bacon- la historia eclesiástica constituye una rama independiente de la historia civil. Esto es fácil de comprender. Tanto Diderot como D'Alembert consideran el orden sagrado como si fuera distinto del orden humano y de ningún modo pueden compartir el interés de Bacon por mostrar la injerencia divina en los asuntos humanos. Es, entonces, claro el límite entre lo sagrado y lo profano en asuntos históricos.

Es de esperar que el artículo "Histoire" que Voltaire escribe para la Enciclopedia responda al marco conceptual allí generado. Sin embargo, quiero destacar tres elementos. En primer lugar, es un trabajo en el que priva una actitud básicamente escéptica. En segundo lugar, dedica gran espacio para sentar las bases de lo que sería una creencia racional. Y por último, no encontramos allí el hilo teórico que nos conduzca en sus obras históricas, Voltaire no nos habla ni del "espíritu de los pueblos", ni de los usos ni costumbres de las naciones, ni del progreso de la razón en el tiempo.

En principio, Voltaire traza una línea rígida entre historia y fábula, engloba con este concepto leyendas, mitos y "cuestiones religiosas". La creencia religiosa de ningún modo es una creencia racional. Sólo la ignorancia justifica su presencia y es suficiente el "desarrollo de la sana razón" para desecharla. De allí que Voltaire llama "mentirosos" a personas como Bossuet o Fleury puesto que no se puede ser culto y creer en los milagros simultáneamente. De este modo, Voltaire reenvía el problema de la fe y los milagros al ámbito de lo irracional.

Sin embargo, hasta el presente, las historias refieren "tanto prodigios como sucesos naturales", por lo que se debe discriminar lo que él denomina historia profana de la historia sagrada. Los hechos de la historia sagrada pertenecen a un orden distinto y aunque "no podamos creer en la verdad de los mismos por la razón" nos sometemos a ellos por la fe. Los hechos narrados no son verdaderos ni falsos, y puesto que sólo deben ser creídos, no hay que juzgarlos de acuerdo con la razón. Por lo que, las acciones divinas no deben mezclarse en la narración de los asuntos humanos. Hasta aquí Voltaire se mantiene dentro del orden que la Enciclopedia instaura para la historia, reforzando la dicotomía historia sagrada/historia profana presente en el "árbol del conocimiento".

Sin embargo, en el artículo que venimos analizando, Voltaire arroja la historia a un estado de incertidumbre total y cualquier ocasión es propicia para señalarlo. Se encarga de mostrar que ni la tradición oral nos conduce a la certeza ni los monumentos constituyen "testimonios irreprochables" de 
eventos históricos. Los orígenes de toda historia los constituyen los relatos, transmitidos de generación en generación, que los padres narran a sus hijos. Estos relatos no son "más que probables en sus orígenes, mientras no choquen con el sentido común, y pierden un grado de probabilidad con cada generación", ${ }^{18}$ hasta que la verdad se pierde por completo. De allí que todos los orígenes de los pueblos sean inciertos. Por ello, finaliza afirmando que las verdades en historia "sólo son probabilidades" y el historiador, al igual que un juez, "no podrá jactarse de conocer perfectamente la verdad". 19 Ésta es, a mi entender, la crítica de Voltaire a una larga tradición que emparenta la historia con la memoria. Y la ruptura se encuentra en el seno mismo de la Enciclopedia. De una historia derivada enteramente de la memoria, cuyo objeto es el recuento de hechos, no obtenemos nada más que probabilidades. Del fin principal de este tipo de historia - los hechos- nunca tendremos certeza, sólo probabilidad.

Lo que Voltaire entiende por historia no encuentra en la Enciclopedia un espacio epistemológico adecuado. En primer lugar, saca a la historia del dominio de la memoria. Tal como la entiende Voltaire, la historia no es mera sucesión de hechos pasados ni el detalle de acontecimientos "casi siempre desfigurados". ${ }^{20}$ Los nuevos criterios de selección asignan a la razón un papel activo y preponderante no sólo a la hora de determinar "lo que pudo haber ocurrido" sino también en la elección de los hechos que merecen ser contados y transmitidos a la posteridad. Para Voltaire, la historia "debe ser escrita por filósofos" y no por historiadores acostumbrados a "reunir una multitud enorme de hechos que se sobreponen unos a otros". ${ }^{21}$ Y esta historia presidida por la razón que busca discernir entre los hechos, el "espiritu" que los anima, pertenece a un género diferente que no encuentra cabida en el "árbol del conocimiento". Un nuevo espacio ha sido instaurado, y tan consciente es de ello, que Voltaire acuña el nuevo nombre de "filosofía de la historia".

De este modo ya no importa para Voltaire que los hechos históricos sean meramente probables y que esta falta de certeza arroje una sombra de escepticismo sobre la historia. Ya no importa, pues el objeto de la historia es distinto, no es historia de hechos fundada en la memoria, sino es "la historia del espíritu humano dirigida a la razón". Una historia plagada de hechos cuya veracidad no se puede comprobar es una historia falsa, una fábula —en tanto relato de hechos falsos. Sin embargo, la "nueva" historia

18 Loc.'cit.

19 Voltaire, Dictionnaire philosophique, vol. 8, art. "vérite", p. 287.

- 20 Voltaire, Remarques pour servir de supplément à l'Essai sur le maurs et l'esprit des nationes, Paris, 1763, p. 47.

21 Loc. cit. 
no puede nunca caer en fábula, a lo más en el error, puesto que "hay muchas falsedades en los historiadores, pero errores en los filósofos".

Si en el artículo "Histoire" de la Enciclopedia buscamos el hilo que nos conduzca a lo que Voltaire entiende por historia, paradójicamente nos lleva en la dirección contraria. Es allí donde, asumiendo el concepto de la tradición, lo critica y lo enfrenta. Pero si la "filosofía de la historia" no tiene cabida en el "árbol enciclopédico", no es sólo por el nuevo papel que le asigna a la razón en un ámbito que hasta ahora estaba reservado a la memoria. Se trata, además, de un viraje que conduce a lo que la modernidad comienza a entender por historia.

Sólo una alusión al principio del artículo - aparentemente marginalnos indica la magnitud de la ruptura: "La historia natural, la parte más importante de la Enciclopedia, que impropiamente se llama historia, no es más que una parte esencial de la física."22 Voltaire separa las artes y oficios del ámbito de lo natural; la historia fundamentalmente humana, acaba de nacer.

III

El ejemplo que venimos discutiendo me permitirá considerar ahora las siguientes cuestiones -esbozadas en la introducción - con respecto a la racionalidad de los cambios científicos:

1. El concepto de racionalidad se determina desde su contexto histórico. En este contexto la racionalidad se define a partir de los elementos que una determinada comunidad reconoce como extraños (irracionales). El paradigma compartido por los "nuevos" historiadores se define, en parte, por oposición a la presencia de lo sagrado en la historia. El milagro, la fábula, lo teológico constituyen lo irracional, el límite de lo irreal. Notemos que, sin embargo, lo sagrado no tiene el mismo estatus de extraño para los miembros de otra comunidad: el mundo de Newton está pleno de Dios. En el paradigma compartido por la comunidad científica, lo religioso no constituye un elemento "conflictivo", lo "otro". El hecho de que este elemento -lo sagrado- desempeñe papeles distintos en los paradigmas de comunidades diferentes, podría sugerir una falta de comunicación entre ambas comunidades. Sin embargo, existen otros elementos que nos permiten inferir una activa interacción. Voltaire rompe con el modelo de historia presidido por la memoria, introduciendo la razón como principio metodológico.

El impacto de Newton en Voltaire es bien conocido. Sin embargo, aún medio siglo después de la publicación de los Principia, la adhesión de Voltaire a Neston provocaba escándalo en Francia, dado que aún era fuerte

22 Loc. cit. El subrayado es nuestro. 
el cartesianismo. Importa menos discutir aquí la continuidad o no entre Newton y Descartes, que considerar el impacto que ejercieron en comunidades diferentes a las suyas. No nos interesa el pensamiento verdadero de Newton, sino la lectura que de él efectuó Voltaire y cómo lo incorpora al nuevo paradigma histórico.

Para Voltaire, Newton representaba la síntesis entre la razón y los hechos, el triunfo del método experimental y de la ciencia progresiva; por el contrario, Descartes simbolizaba la falacia de querer someter la física a la metafísica. Esta interpretación y su divulgación constituyen, ya, un hecho histórico. Efectuada la lectura desde su esquema conceptual, Voltaire fue ajeno a la fundamentación teológica y metafísica de la concepción newtoniana del universo. Directamente, la ignoró. Quiero en este punto admitir cierto grado de inconmensurabilidad, una inconmensurabilidad parcial entre paradigmas de comunidades socioculturales contemporáneas. La interacción activa entre dos o más paradigmas de diferentes comunidades contemporáneas no significa que todos los elementos de un paradigma puedan ser leídos o interpretados desde el otro paradigma. En ocasiones, existen ciertos elementos en uno que son, o bien conflictivos para el marco conceptual del otro paradigma o bien desde este marco no se pueden "leer", lo que permitiría hablar de inconmensurabilidades parciales entre paradigmas.

2. Si contextualizamos la racionalidad - los miembros de una comunidad son racionales en tanto coherentes con su sistema conceptual-, habrá elementos con los cuales esa comunidad mantendrá una relación de ceguera y no de oposición por ser éstos avant la lettre. En el caso que analizamos, dicho elemento está representado por la concepción histórica de Vico. Lo que precisamente niega Vico es esa división rígida entre historia y fábula establecida por Voltaire y los enciclopedistas. Para Vico lo verdadero y lo fabuloso son dos modos diferentes que tiene el hombre de relacionarse con el mundo. Estos elementos "ajenos" no generan relaciones que contribuyan a configurar el marco de sentido o episteme, permanecen marginales; por lo que sólo pueden ser identificados o "leídos" desde otra espisteme. Así, Vico es "descubierto" por el romanticismo.

3. Los cambios en las diferentes comunidades no se producen simultáneamente. Con relación al ejemplo estudiado, Newton termina lo que Kepler y Galileo habían comenzado: la ordenación matemática del universo. Los Principia se publican en 1686 y representan la culminación de esta visión homogénea y cuantitativa de la naturaleza. Sin embargo, sólo cinco años antes había aparecido el Discours sur l'histoire universelle de Bossuet, exponente de la concepción teológica de la historia: faltaba más de medio siglo para la aparición del nuevo paradigma histórico. 
4. Son los cambios de las diferentes comunidades en su conjunto $-y$ no sólo los de la comunidad científica- los que proveen las relaciones de sentido que constituyen las grandes epistemes. Los cambios de estas últimas son procesos de larga duración, cuyas unidades de cambio son los cambios producidos en el interior de las comunidades. En los procesos de transformación de las grandes epistemes, podemos distinguir comunidades epónimas. ${ }^{23}$ Denominamos así a aquellas comunidades cuyos paradigmas ejercen una mayor influencia en el establecimiento de las redes conceptuales de los demás paradigmas. En nuestro caso, dicho papel estaría representado por la comunidad "físico-natural". El espacio instaurado por una episteme no es, en modo alguno, homogéneo. Coexisten en su interior unidades, algunas de las cuales muestran una relación de oposición, otras de cohesión, muchas de sucesión.

5. Admitimos, entonces, la posibilidad de incomensurabilidades parciales entre paradigmas sucesivos de una comunidad o entre paradigmas coexistentes de comunidades socioculturales diferentes pertenecientes todos, por ejemplo, a una misma episteme. Sin embargo, esto no impide reconocer cierto grado de racionalidad que es el presupuesto básico para que el pasado sea inteligible y constituye la condición de posibilidad de la historia epistémica, en particular, y de la historia, en general. Habrá historias de ciencias, historias de historia, historias de religiones, pero en todas subyace la idea de un pasado al que podemos acceder si presuponemos una racionalidad que se constituya en principio de inteligibilidad.

23 Tomamos el término de Ortega y Gasset, En torno a Galileo, Revista de Occidente, Madrid, 1976, p. 73, que lo utiliza para su método histórico de generaciones. 